\title{
The burden of the moment:
}

\section{Photography's inherent}

\section{monumentalizing effect}

\author{
Peter Burleigh
}

When we look at photographs, we unfailingly feel the inescapable lure of time past. This impression is dependent on the mimetic indexicality central to the medium. Mimetic, since a photograph appears in almost all cases to resemble that which it represents; indexical, since to a great extent the relation between the photograph's light-sensitive material and the object it pictures is a natural one. Thus a photograph appears to faithfully and non-arbitrarily record its subject, and, furthermore, to reiterate the very moment of its making - a moment we reaffirm even when we do as little as glimpse an image.

The experience, however, is not solely ocular, and a respectable body of criticism has explored the relationship between the visual and the material, yet always reflecting on the role time plays in the photographic. In his later writing Barthes invokes the "that-has-been," and embarks on a discourse of envisioned memory (77), while Benjamin emphasizes the "tiny spark of contingency," (243) exploring the coincidental yet historical situating of whatever a photograph pictures. Even from the beginning of the writings on photography, notions of time have been coupled to this practice. The words of Henry Fox Talbot in 1839 suggest how from photography's inception its interplay with time has been crucial to an understanding of the medium: "[T]he most transitory of things, a shadow, proverbial the emblem of all that is fleeting and momentary, may be fettered by the spells of our natural magic, and may be fixed forever in the position which it 
seemed only destined for a single instant to occupy" (41). While recognizing Talbot's fancy as a point of departure and giving due respect to Barthes and Benjamin, I contend that whether the past is prosthetically re-enacted as a memory, as a coincidence, as the ephemeral, photography can be seen as a form of desire to 'reterritorialize' its subject.

Reterritorialization is a concept developed by Deleuze and Guattari to understand the way in which appropriated spaces are rearticulated or readopted by populations through lived experience or the reshaping of artefacts. Transferring this notion from social action to representation is legitimate since Deleuze and Guattari claim "anything can 'stand for' the lost territory; one can reterritorialize on a being, an object, an apparatus, a system" (Buchanan, 30). Key to reterritorialization is that a new type of territory is produced. In these terms then, the photograph does not return to an earlier space or time through a representation of there and then, but introduces a new token that can be a 'meaningful' territory itself. Thus, the making of the photograph folds lived experience onto and out into a flat smooth space, a new space, the monument that is significantly different from the volume it figures and is a transformation of the moment it represents. Photography rearticulates that which is continuously seized from us: time; turning it into a tangible, haptic form of memorial. Nonetheless, the turning of moment into a monument is acted out in differing ways and with considerably different effects by different practitioners.

To review the notion of reterritorialization in photography, I want to look at three very different practices, and examine how they each deal with the transfiguration of a moment into a spatial arrangement. The surrealist imagery of Cartier-Bresson's work stands at odds with the "straight" discipline in which he claims photography has a role to enact "a simple factual testimony," the picturing of the "one moment at which the elements in motion are in balance" (n. pag.). His photographs - whether each seen individually, or as a total assemblage - monumentalize the human world in an encyclopaedic sum of particular, unique moments. With the typological work of Bernd and Hilla Becher, we see a unification of practice, form and content in the apparent denial of the contingency of the photographer's presence in space and time. Quite in opposition to the photographs captured in Cartier-Bresson's "decisive moment," their images initially strike one as seeming to be made entirely independently of a momentary instant, appearing to be always already the same and reiterable. The Bechers' motivation is one of the preservation and conservation of that which is disappearing, rather than the capturing of the moment in which a scene is compositionally and symbolically in balance. In a sense, their work is the attempt to sum many individual moments into a mass of history. Finally, in the collections and installations of Wolfgang Tillmans, the photographer 
appears to turn everyday, insignificant instantaneity into a found, precious moment. Not the avid voyeur of Cartier-Bresson, nor the historian of the Bechers, Tillmans represents contemporary everyday absurdities almost as 'case studies' where the personal becomes monumental, where images in patterns, constellations and sheer number stretch out the personal lived moment into a concertina of equivalents. The feeling in Tillmans' work is that a narrative is about to unfold from, around and between the images. Rather than reflecting on the moment that has disappeared, or the passing of time, Tillmans focuses on the nowness of moments, and is intent on making an image that is consistent both reflexively and extensively with other images rather than simply with what it pictures. In his work, then, any particular moment becomes a necessary yet trivial feature of the photographic image.

In Images à la Sauvette, translated into English as The Decisive Moment, Cartier-Bresson argues for a photography that addresses "Things-As-TheyAre," prefacing his essay on the modus operandi of the photographer with the now infamous quote of Cardinal de Retz, "there is nothing in the world that does not have a decisive moment" (n. pag.). In Cartier-Bresson's notion of his practice, the straight, exposed-with-available-light, uncropped image is an unadulterated view of the material world out there. As Jerry N. Uelsmann states: “The 'straight tradition' implies that the image is basically fully conceived at the camera” (444). In Cartier-Bresson's case, this conception occurs in the split moment before the scene perfectly unfolds in compositional form, tension, movement, light and texture. In photography, Uelsmann continues, "there is a decisive selecting of a fragment of life in flux, [a] way in which the camera can preserve that moment and allow us to study it in ways which we could not do otherwise" (443). In this formulation, the image is understood as inseparable from its moment of making, is an empirical mirroring of a "world out there," as Cartier-Bresson states, "simply register(ing) upon film the decision made with the eye” (n. pag.).

Andalusia (1933) is one of Cartier-Bresson's earliest images and typifies much of his work (fig. 1). We see a layered zigzag of walls, the corners of alleyways, and high-noon shadows creating a busy geometric backdrop to an enclosed space for the scene unfolding in the foreground. Shadows and highlights are carefully balanced so that the powderiness of the decaying walls, the lines of stonework running along the alleyways, even the slats of the window shutter are distinguishable, lending the image texture and geometry at a micro level.

Foregrounded in the shadow to the right, with a splash of sunlight catching his cropped hair and running down his right upper torso, stands a young boy, motionless; his gaze is down- and rightwards leading us in the direction of the second figure, a much younger and smaller boy, 


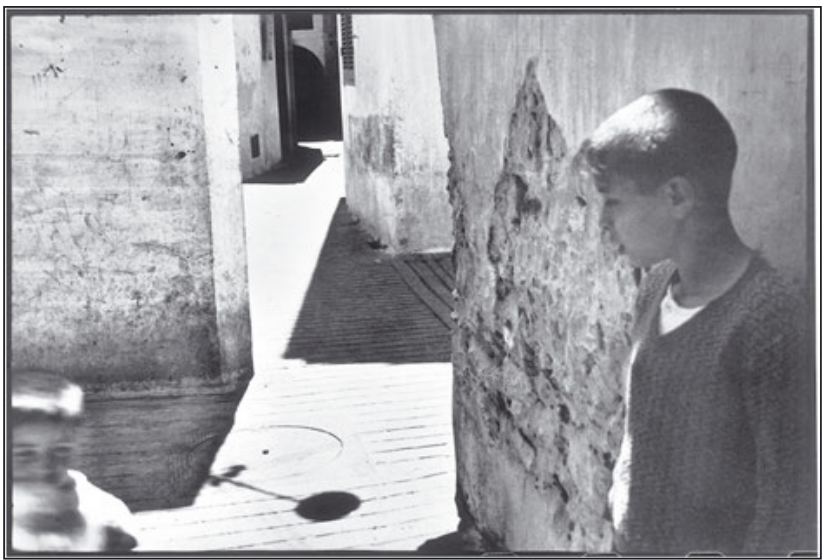

Figure 1: Henri Cartier-Bresson, Andalusia (1933). (C) Magnum.

caught moving in the bottom left of the image. Between the two figures lie the grey-tone outline of a drain cover and a deep black shadow. The two circular forms, one a line, the other a block of colour resonate harmonically with the round heads of the two boys, reflecting and amplifying, on the one hand, stasis - the boy in shadow and the fixed outline - and, on the other, movement - the boy in motion and the momentarily fixed, sluggish shadow, lent velocity by the younger boy's dynamic form. A moment is captured at many different levels: specifically at midday; precisely as one figure is stationary and the other moving; at a biographical phase in the young boy's life, perhaps at the cusp of puberty. This moment may even be construed as a juncture when the everyday stands metaphorically for the celestial. Such a tableau, consciously constructed, abstracted from the lived moment, invites a symbolic reading. Thus what really turns this moment into a decisive one is the perfect arrangement of geometrical shapes that furnishes the photograph with the potential for a meta-reading: here, I suggest, the circular geometry as a metaphor for planetary rotation. Only in that fractional slice of time did a moving arbitrary scene turn into a composed tableau in Cartier-Bresson's visual inventory.

In the Bechers' work, dating from the early 1960s, the intention to present and bring forth a pre-visualized concept is explicitly expressed and marks a point of departure at odds with Cartier-Bresson's 'moment'. Patricia C. Phillips states: "The drama of these photographs does not come from the play of light and shadow but from the suspension of movement. It is the grand stillness of these industrial beasts that captivates and confuses" (114). For here the tension that inheres in their images is one between the seeming arbitrariness of the object pictured, and the photographers' deliberate choice of the artefacts of an industrial culture now redundant, 
derelict and under the threat of erasure, documented with an exactitude such that the whole set of images is, as Susan Lange puts it, "a means of visually comprehending an industrial site as a whole” (n. pag.). We find neither the accidental happy moment, nor the deliberately snared scene of Cartier-Bresson. Instead, the Bechers' photography both extends the presence of a particular moment in the process of making, while eradicating the particularity of moment in the finished product, a replica of that which is monumental. ${ }^{1}$

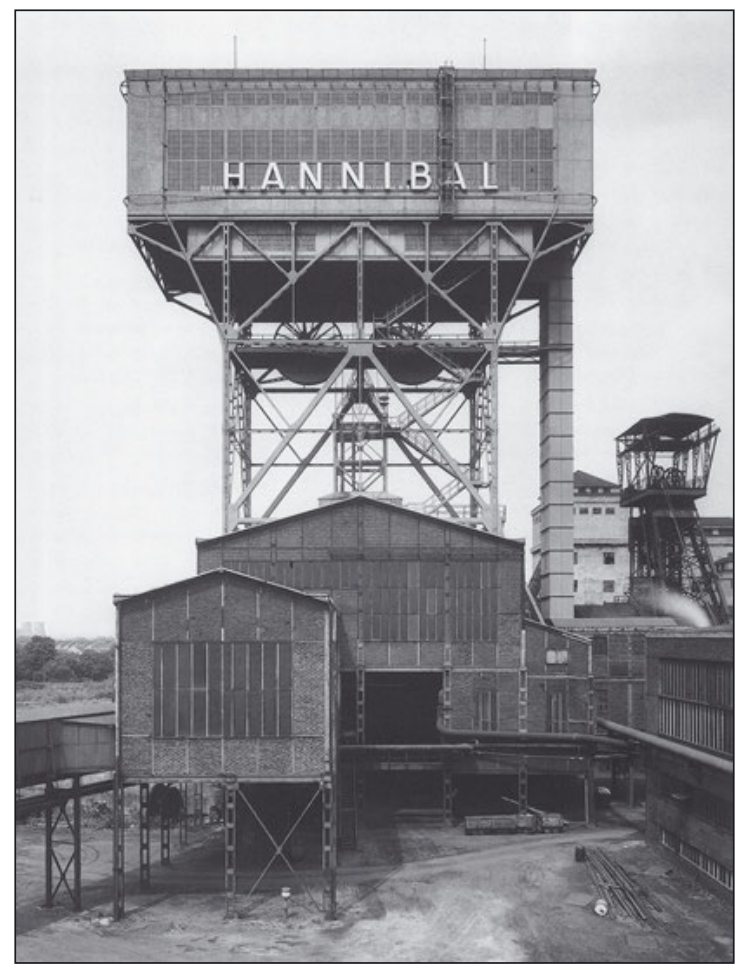

Figure 2: Bernd and Hilla Becher, Zeche Hannibal (1971). (C) Bernd and Hilla Becher Schirmer/Mosel Verlag.

Photographs of the Zeche Hannibal (1971) are typical (fig. 2): The light of overcast, dull days which allows grey tones to appear in their full range, with the architectural outline of structures sharply defined against a flat grey backcloth entail that contingency is not simply reduced to a minimum but virtually disappears: the pictorial values in their images all appear to be similar, and the circumstances at the moments of taking were also

1 I am indebted to Sophie Jung for the original notion expressed here. 
similar; the precise moment of photographing, however, was or is unique on two counts. Firstly, the technology of photography necessarily imposes constraints on the making of the image, and the requisite long exposure times mean the Bechers made their images counting out the exposure times over seconds. So each photographing is a unique and knowable experience for them, and what is more, gives back authentic time to its object, turning monument into moment. Secondly, the photographs reference the unrepeatability of moments, drawing our attention to the passing of time, and the attendant processes of decay and disappearance. As Birnbaum reports them as saying, "since these structures were disappearing more and more, we could imagine that conserving them photographically would some day be of general interest" (Birnbaum, 204). Their photographs both mark and resist disintegration by articulating structure and organisation, and visualizing the condensation of labour into specific historical material forms identified by place and date - showing us what had been done, and what can be documented and remembered against the progression of time: each object pictured has social and economic history - is typical yet unique.

Displaying their photographs in series, as, for example, in Fördertürme (1973) (fig. 3), the Bechers focus on both similarity and difference, on the uniqueness of the individual 'thing' pictured, and on its conformity to type. Because their visual apparatus seems to become transparent through repeatedly using the same compositional criteria, the Bechers' camera claims a trans-historical objectivity. Every detail is reproduced with perfect clarity and could be made again and again, liberated of a specific "Cartier-Bresson" moment. It is not then singular moments which are reterritorialized - transformed into visual, spatial arrangements. Rather just as the images are presented as series of summed unique forms which together in their overlapping qualities identify either a type, or thoroughly describe a token of a type, so are moments summed together as time in general, or as a distillation of history. The Bechers' work thus focuses on a representation of the thing itself in Place and Time. In Cartier-Bresson's uniquely captured moment, the focus is on the rarity of the instant in which "the photographer must make sure, while he is still in the presence of the unfolding scene [...] that he has really given expression to the meaning of the scene in its entirety, for afterwards it is too late" (n. pag.). While the Bechers also photograph scenes before it is too late, their period is of a longer duration and documents that which is already monumental.

From the 1990 s on, Wolfgang Tillmans has produced a variety of photographic work: portraits, still lifes, abstract images, all of which, arranged in book editions or room installations, are his "way of making the camera do what I want it to do" (Tillmans, "What they are" 67 ). This is 


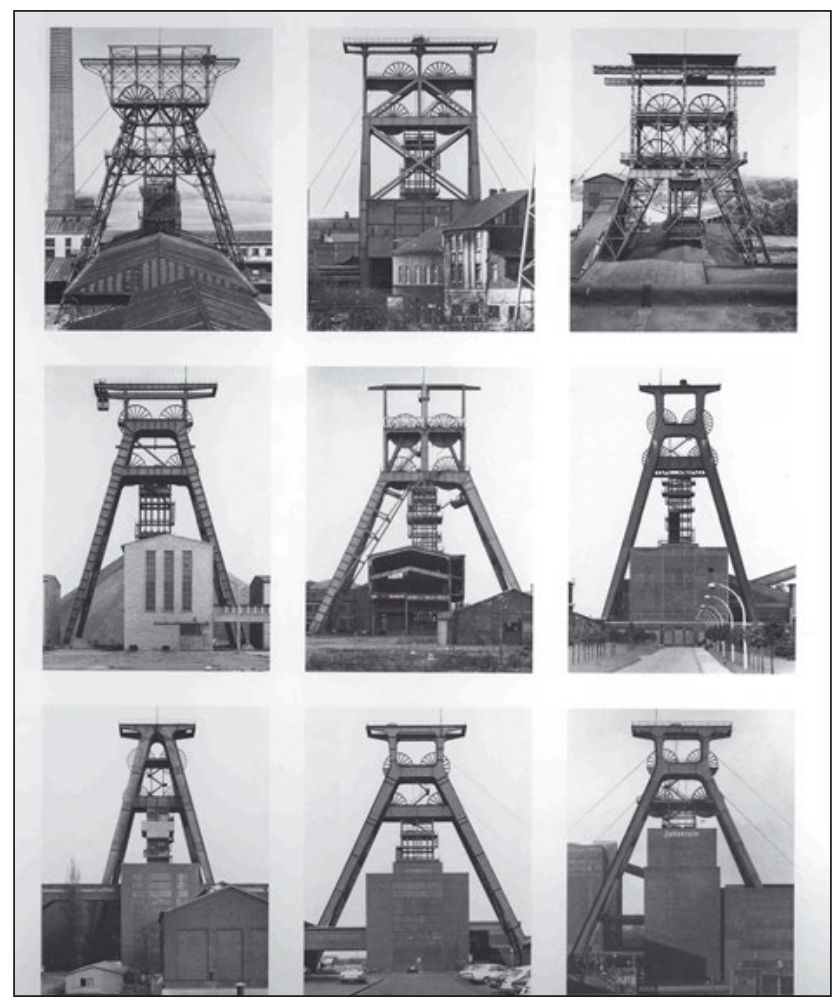

Figure 3: Bernd and Hilla Becher, Fördertürme (1973).

(C) Bernd and Hilla Becher Schirmer/Mosel Verlag.

his recognition of the process and outcome of reterritorializing moments into images, when "a very of-the-moment, in-the-moment readiness of the camera is the only way for the camera to be" $(65-67)$. For Tillmans the event structure itself and its resultant image is key. In direct contrast to Cartier-Bresson's view that "of all the means of expression, photography is the only one that fixes forever the precise and transitory instant" (n. pag.), Tillmans states: “That it does happen now, here, this second doesn't make it any better or more authentic" (67). This then means that he can use interchangeable moments or equivalents to compose one longer moment that becomes conceptually monumental. He understands his photography as being "almost on the border between something and nothing; [asking] when does 'something' become 'something ... else'?” (63). The liminal performance of something appearing is the transition from moment to monument. And if the repeatable, exchangeable moments are in Tillman's words "all real because they all happened in front of the camera. But then at the same time they are all constructions, they are not real, they 
are photographs" (67), then it is the observer who must make sense of the images by reconstructing them into an inter-relationship in the now.

The observer's necessary involvement is clear, for example, in friends (WMF), 2000 (2005), which makes sense only when seen in relation to friends (smoke), 2004 (2005) and other images in the book Truth Study Center. Here we see a moment which cannot be described as extraordinary; flash lighting flattens textures and heightens contrasts, a short lens stretches out the foregrounding, bringing the Beck's beer bottle, table and soles of the trainers much nearer to us, while pushing the plane of the figures of subjects further away (fig. 4). Compositionally, in this plane, there is a cascade of form from left to right; the knot of three figures unwraps across the image into one then another individual. The intimate contact between the woman with her back to us, her upper thigh caressing the black-jeaned knee of a man, her buttocks on the lap of a second, gives way to two men who confront the viewer. The comfort of the individuals, their togetherness, and equivalence is brought out when that photograph is compared with the consecutive image. For in friends (smoke), we see four men in close contact, two figures hugging one another, no eye contact is made with the observer. Faces are turned away, partially or totally obscured; gazes are within the image. Cigarettes and the hands holding them appear equivalent, which belongs to whom is not immediately clear; army-fatigue style jeans and cropped hair repeat the equivalence trope (fig. 5). Now the relationships pictured here also make sense when we look at Strümpfe, 2002 (2005) placed further on in the book, but taken chronologically between the other two images (fig. 6).

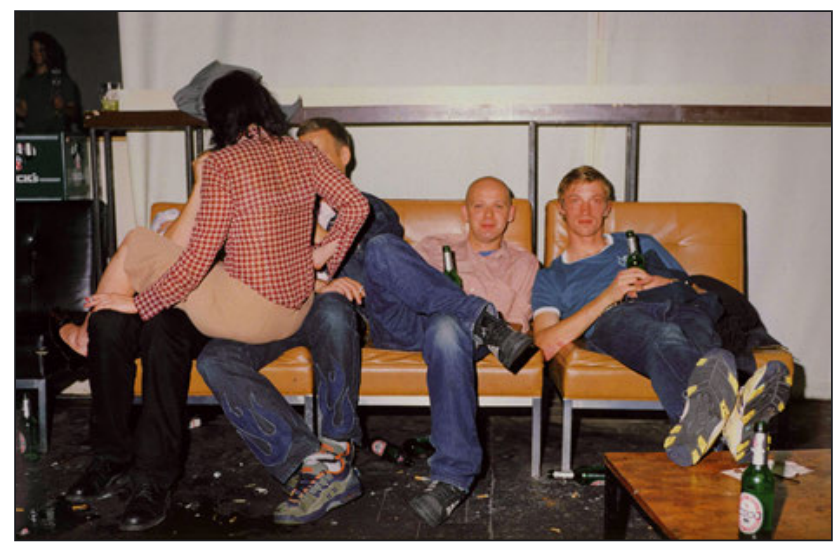

Figure 4: Wolfgang Tillmans, friends (WMF), 2000, 2005. Courtesy of the artist. 


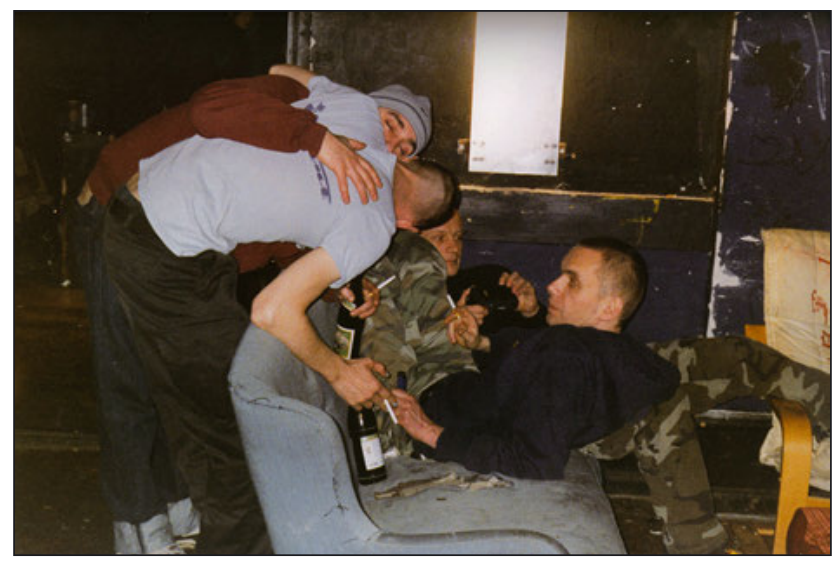

Figure 5: Wolfgang Tillmans, friends (smoke), 2004, 2005. Courtesy of the artist.

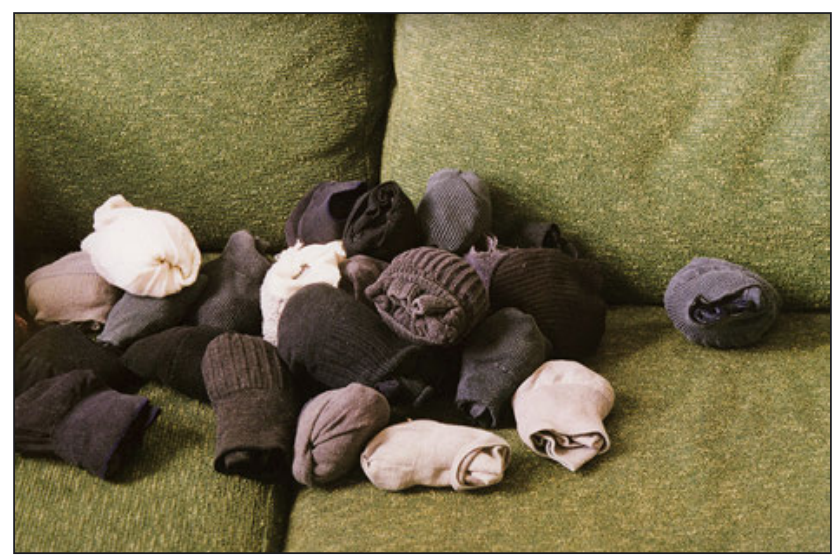

Figure 6: Wolfgang Tillmans, Strümpfe, 2002, 2005.

Courtesy of the artist.

Here, an assemblage of moments is overwritten with metaphors of belonging and togetherness: the socks are paired; none of them is lonely. They belong together in a community in conversation with each other. A small group to the left are arranged differently in relation to one another: more distant than in the main bundle, but they still belong to the whole community. On the right, a single pair lies separate and quite distinct from the main group. Looking again at friends (WMF) and friends (smoke), we see equivalences assemble a group, which nonetheless unfolds into individuals. And this is key to Tillman's photography, since he argues "I am not gathering memories. The point is not to possess or experience something by seizing it with the camera" (Tillmans, Truth Study Center n. pag). Rather, Tillmans returns 
us to my opening proposition that photography is a reterritorialization. In his work the moment is circular, enclosed, endocentric. He claims that his practice is to "transform something simple, or even something complicated, into something else" (Tillmans, "What they are" 64), and with these words he mirrors the notion of reterritorialization. Where the Bechers turn a moment into a replica, where Cartier-Bresson turns a moment into a constructed tableau, Tillmans stretches moments into one open-ended metaphor.

The breadth of photographic practice does not allow for a monolithic understanding of this transfiguration, and perhaps the notion of creative purpose needs to be more clearly identified. Even three, albeit key, figures in photography demonstrate differing sensibilities toward time and its transformation into space. With Cartier-Bresson, photography captures a moment; with the Bechers photography addresses the summation of time as history; in Tillmans, photography becomes a practice of equivalence. Each reclaiming, reforming and folding out of time into space in photography gives expression to different kinds of monumentalizing.

\section{References}

Barthes, Roland. Camera Lucida. Trans. Richard Howard. London: Fontana, 1984 .

Batchen, Geoffrey. Burning With Desire: The Conception of Photography. Cambridge: The MIT Press, 1997.

Becher, Bernd and Hilla Becher. Typologien. München: Schirmer/Mosel, 1999.

Becher, Bernd and Hilla Becher. Zeche Hannibal. München: Schirmer/ Mosel, 2000.

Benjamin, Walter. "A Small History of Photography." Trans. Edmund Jephcott and Kingsley Shorter. One-Way Street. London: Verso, 1997. 240-257.

Birnbaum, Daniel. "Bernd and Hilla Becher." Review of Typologies, an exhibition of typological photographs of industrial architecture (Düsseldorf, K21-Kunstsammlung Nordrhein-Westfalen, 2004). By Bernd and Hilla Becher. Artforum (May 2004): 202-204.

Buchanan, Ian and Greg Lambert, eds. Deleuze and Space. Edinburgh: Edinburgh University Press, 2005.

Cartier-Bresson, Henri. "Introduction." The Decisive Moment. By Henri Cartier-Bresson. Trans. Margot Shore. New York: Simon \& Schuster, 1952. 
Goldberg, Vicki, ed. Photography in Print. Albuquerque: University of New Mexico Press, 1981.

Lange, Susan \& Els Barents. Trans. Gabriele Westphal. Introduction. Zeche Hannibal. By Bernd and Hilla Becher. München: Schirmer/Mosel, 2001.

Phillips, Patricia C. Review of New York openings. Artforum (March 1986): 114 .

Shimizu, Minoru. “The Art of Equivalence.” Afterword. Truth Study Center. By Wolfgang Tillmans. Köln: Taschen, 2005.

Talbot, William Henry Fox. "Some Account of the Art of Photogenic Drawing." London and Edinburgh Philosophical Magazine and Journal of Science (March 1839): 14. Reproduced in Photography in Print. Ed. Vicki Goldberg. Albuquerque: University of New Mexico Press, 1981. 36-48.

Tillmans, Wolfgang. Interview with Mary Horlock. Wolfgang Tillmans. If one thing matters, everything matters. Ostfildern: Hatje Cantz, 2003.

Tillmans, Wolfgang. Interview with Nathan Kernan. "What they are: a conversation with Wolfgang." Art On Paper (May-June 2001): 60-67.

Tillmans, Wolfgang. Truth Study Center. Köln: Taschen, 2005.

Uelsmann, Jerry. “Some Humanistic Considerations of Photography.” The Royal Society, London. 1971. Photography in Print. Ed. Vicki Goldberg. Albuquerque: University of New Mexico Press, 1981. 442-451.

\section{Illustrations}

Becher, Bernd and Hilla Becher. Fördertürme. 1973. Typologien. By Bernd Becher and Hilla Becher. München: Schirmer/Mosel, 1999.

Becher, Bernd and Hilla Becher. Zeche Hannibal. 1971. Zeche Hannibal. By Bernd Becher and Hilla Becher. München: Schirmer/Mosel, 2000.

Cartier-Bresson, Henri. Andalusia. 1933. The Decisive Moment. By Henri Cartier-Bresson. New York: Simon \& Schuster, 1952.

Tillmans, Wolfgang. friends (WMF), 2000. 2005. Truth Study Center. By Wolfgang Tillmans. Köln: Taschen, 2005.

Tillmans, Wolfgang. friends (smoke), 2004. 2005. Truth Study Center. By Wolfgang Tillmans. Köln: Taschen, 2005.

Tillmans, Wolfgang. Strümpfe, 2002. 2005. Truth Study Center. By Wolfgang Tillmans. Köln: Taschen, 2005. 
Bereitgestellt von | Universitaetsbibliothek Basel

Angemeldet

Heruntergeladen am | 18.09.18 17:58 